\title{
Universiteit
}

Leiden

The Netherlands

\section{Drivers of spontaneous plant richness patterns in urban green space within a biodiversity hotspot}

Gao, Z.; Song, K.; Pan, Y.; Dan, M.; Zhang, X.; Jia, B.; ... ; Cieraad, E.

\section{Citation}

Gao, Z., Song, K., Pan, Y., Dan, M., Zhang, X., Jia, B., ... Cieraad, E. (2021). Drivers of spontaneous plant richness patterns in urban green space within a biodiversity hotspot. Urban Forestry And Urban Greening, 61. doi:10.1016/j.ufug.2021.127098

Version: $\quad$ Publisher's Version

License: $\quad$ Licensed under Article 25fa Copyright Act/Law (Amendment Taverne)

Downloaded from: https://hdl.handle.net/1887/3238905

Note: To cite this publication please use the final published version (if applicable). 


\title{
Drivers of spontaneous plant richness patterns in urban green space within a biodiversity hotspot
}

\author{
Zhiwen Gao ${ }^{a}$, Kun Song ${ }^{\text {b, c, } * \text {, Yingji Pan }}{ }^{\mathrm{d}}$, Dan Malkinson ${ }^{\mathrm{e}}$, Xijin Zhang ${ }^{\mathrm{a}}$, Bo Jia ${ }^{\mathrm{a}}$, Tiyuan Xia ${ }^{\mathrm{f}}$, \\ Xueyan Guo ${ }^{a}$, Hong Liang ${ }^{g}$, Shasha Huang ${ }^{a}$, Liangjun Da ${ }^{\text {b, }, *}$, Peter M. Van Bodegom ${ }^{d}$, \\ Ellen Cieraad $^{\mathrm{d}}$ \\ ${ }^{\text {a }}$ School of Ecological and Environmental Sciences, East China Normal University, Shanghai, 200241, China \\ ${ }^{\mathrm{b}}$ Shanghai Key Lab for Urban Ecological Processes and Eco-Restoration, Tiantong National Forest Ecosystem Observation and Research Station, School of Ecological and \\ Environmental Sciences, East China Normal University, Shanghai, 200241, China \\ ${ }^{\mathrm{c}}$ Institute of Eco-Chongming, Shanghai, 200062, China \\ ${ }^{\mathrm{d}}$ Institute of Environmental Sciences (CML), Leiden University, Einsteinweg 2, 2333 CC, Leiden, the Netherlands \\ e Department of Geography and Environmental Studies, Shamir Research Institute, University of Haifa, Mount Carmel, Haifa, 3498838, Israel \\ ${ }^{\mathrm{f}}$ Department of Science and Technology, Kunming University, Kunming, 650241, China \\ ${ }^{\mathrm{g}}$ College of Landscape Architecture and Forestry, Qingdao Agricultural University, Qingdao, 266109, China
}

\section{A R T I C L E I N F O}

Handling Editor: Tenley Conway

\section{Keywords:}

Species richness

Spontaneous plants

Urbanization

Urban greening

\begin{abstract}
A B S T R A C T
Urban green space provides refuges for species that are unintentionally introduced by humans and which do not belong to the remnants of natural habitats in urban areas. However, the quantitative relationships between urban green space properties and these spontaneous species are unclear. To address this, we surveyed plant species occurring in urban green patches in Kunming city, which is located in a biodiversity hotspot in southwest China. We classified spontaneous plants into native, non-native and invasive plant species. A total of 386 spontaneous species belonging to 278 genera and 92 families were recorded in 190 patches. Most of the recorded species were herbaceous plants $(76.2 \%)$. While invasive species constituted a relatively small proportion of the total species pool (17.9\%), six out of ten of the most frequently occurring species were invasive. Regression models inspired by the theory of Island Biogeography show that total, native, non-native and invasive spontaneous species richness in urban green patches were best explained by the size of the 'island' (patch area), dispersal limitations (as expressed by 'distance to city boundary') and edge effects (as shown by the landscape shape index). While the set of drivers of spontaneous plants is similar for the different groups of species, the relative importance of each driver varies among them. Our study provides quantification of drivers of biodiversity patterns in urban green space. Based on this understanding, planning and management of urban green space can be adapted to maximize spontaneous plant conservation in rapidly urbanizing biodiversity hotspot regions.
\end{abstract}

\section{Introduction}

As cities continue to grow, urbanization increasingly modifies the ecological processes and features in urban areas, resulting in a loss of natural habitats and heterogeneity in urban habitats (Zhao et al., 2006; Kotze et al., 2011; Groffman et al., 2014). In addition, humans actively and intentionally plant ornamental plants, while removing unfavorable species and intensively managing others through horticulture activities such as pruning, irrigation, fertilization and weed control. Together, these activities alter both composition and diversity of the urban plant communities (Sudha and Ravindranath, 2000; Ignatieva et al., 2011), and have resulted in highly modified landscapes, which provide less habitat for wildlife (Pickett et al., 2001, 2004).

Urban green spaces encompass all natural, semi-natural and artificial

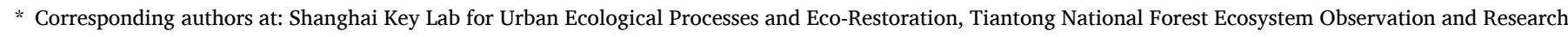
Station, School of Ecological and Environmental Sciences, East China Normal University, Shanghai, 200241, China.

E-mail addresses: godwin-9527@qq.com (Z. Gao), ksong@des.ecnu.edu.cn (K. Song), y.pan@cml.leidenuniv.nl (Y. Pan), dmalk@geo.haifa.ac.il (D. Malkinson),

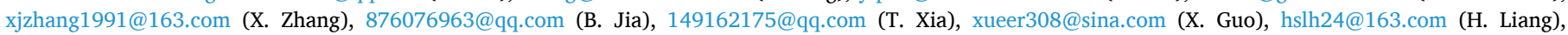

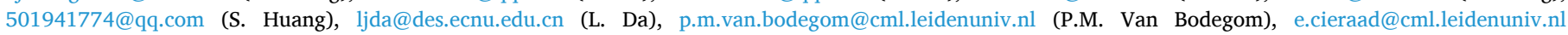
(E. Cieraad).
} 
networks of multifunctional ecological systems. Thus, they include urban parks, abandoned lands, areas of secondary succession, ruderal and pioneer environments, open areas and remnant forests. Urban green space provides important features for biodiversity either as temporary or permanent habitats. They also serve as "corridors" or "stepping stones" to facilitate species dispersal (Baum et al., 2004; Saura et al., 2014; Alharbi and Petrovskii, 2019). They are therefore a key component for ecological urban planning. While it is clear that green space can contribute to protecting and enhancing biodiversity in urban areas (Huang et al., 2019), there is still a lack of understanding of which green space properties, such as patch' size and configuration, promote biodiversity.

Moreover, many rapidly growing cities are situated in biodiversity hotspots. These hotspots contain $44 \%$ of the world's plant species and $35 \%$ of the vertebrate species on only $1.4 \%$ of the earth's land area, and are under threat of ongoing human activities and severe habitat loss (Myers et al., 2000). Currently, it is unclear how urbanization affects biodiversity in these hotspots. A better understanding of the drivers of species richness in such a biodiversity hotspot with very recent and ongoing rapid urbanization may contribute to improved management and protection of biodiversity in urban areas around the world.

Urban vegetation can be classified into three categories: cultivated vegetation which is intentionally introduced by humans, natural remnant vegetation and spontaneous vegetation (Cervelli et al., 2013). The latter is defined as species that are unintentionally introduced by humans and do not belong to the remnants of natural habitats that are a typical component in urban environments (Cervelli et al., 2013). These plant species may grow in any type of urban green space, even in extreme environments such as brownfields, masonry walls, rooftops and pavement crevasses (De Sousa, 2006; Jeremy, 2011; Huang et al., 2019). Most studies in the urban environment have treated spontaneous plant species as invasive alien plants or in relation to weed control (Cavender Bares et al., 2020a, 2020b; Chen et al., 2020; E Silva et al., 2020; Knapp et al., 2017). There is, however, an increasing awareness that spontaneous plants may have important ecological benefits. The idea of fostering these plants as an alternative of ornamental cultivars to construct a sustainable and low-maintenance landscape has been introduced in various studies (Choi, 2004; Del Tredici, 2010; Smith and Fellowes, 2014; Bonthoux et al., 2019). Nonetheless, it has been largely overlooked that spontaneous plant species of different categories (e.g. native species, non-native species and invasive species) may colonize and establish in urban green space in different ways. For example, non-native species may mainly depend on horticultural practices and preferences (Avolio et al., 2020; Cavender Bares et al., 2020a, 2020b), and invasive species mainly disperse by human traffic and transportation(Kendal et al., 2012; Von der Lippe and Kowarik, 2008). In contrast, native species may mainly depend on the regional species pool and the natural environmental conditions. Thus, it is suggested that these different groups of spontaneous plant species may differentially respond to urban environments and morphologies (Zhu et al., 2019).

The driving factors for spontaneous plant diversity and distribution patterns have been well studied at the community scale in urban ecosystems (Chen et al., 2014; Cui et al., 2019). Different light conditions, disturbance intensities, soil depth and moisture contents affect alpha diversity patterns of spontaneous plant species (Cervelli et al., 2013; Li et al., 2019). In addition to these local drivers, the spatial characteristics of the urban green space are also important. Isolation and fragmentation of urban habitats are determined by patch size, shape and its spatial configuration (Peng et al., 2019). Itescu (2018) reviewed different island-like systems in empirical studies and indicated that the fragmented urban green space system was analogous to isolated oceanic islands. Hence, the richness of spontaneous plant species in green space patches may be highly related to the patches' area and their distance to the species pool, as predicted by the Island Biogeography Theory (MacArthur and Wilson, 1967). However, when applied to urban landscapes, the Island Biogeography Theory may have shortcomings as the surrounding matrix is not as hostile as the oceanic matrix and as there is no clear mainland serving as a species pool source (Niemelä, 1999). Thus, in urban areas, the role of distance from the mainland, i.e., patch distance from city boundary, may be of lesser importance. Alternative theories, such as the meta-population theory (Hanski and Gilpin, 1991; Hanski and Ovaskainen, 2000) and the patch-matrix approach (Laurance, 2008) point to the importance of distance and connectivity between two fragments for species richness and may be better suited to account for patch matrix properties. However, none of the three frameworks discussed above explicitly account for patch properties other than size. Thus, geometric properties such as patch shape, perimeter-area ratio and landscape shape, are not accounted for. Finally, the (differential) impact of these patch' and matrix properties on different groups of spontaneous plants is currently unknown and requires additional studies to understand the exact mechanisms affecting urban species richness patterns (Malkinson et al., 2018).

In this study, we assessed the relationship between cityscape structure, namely patch geometry and spatial attributes, and plant richness in the rapidly urbanizing biodiversity hotspot Kunming, China. We also assessed whether these drivers differ between four categories of spontaneous species, namely total, native, non-native and invasive species. We selected patch' properties pertaining to the different theories outlined above, including patch area, distance to city boundary, perimeterarea ratio, landscape shape index, impermeable surface proportion around the patches and distance to the nearest neighboring patch, that may affect species diversity patterns. Due to the concentric structure of Kunming, distance to city boundary was chosen to represent the intensity of urbanization and distance to the regional species pool. Edges can be viewed as transition zones between neighboring patches, therefore the perimeter-area ratio and landscape shape index were selected to assess patches' edge effects. The smaller the area, the more irregular the circumference, the larger the edge effect is expected to be. Matrix resistance affects species dispersal, and for plants in the urban environment this may be quantified as the proportion of impermeable surface around a patch, as a proxy for dispersal or access potential to nearby patches (Malkinson et al., 2018). Neighboring patches can be considered a "stepping stone" for species dispersal. Therefore, distance to the nearest neighboring patch was chosen to represent access potential to nearby patches. Thus, we hypothesize that 1 ) richness patterns of native species will be more strongly affected by dispersal limitations, and thus negatively correlated with distance to the city boundary. 2) Non-native and invasive species, which are introduced into the urban area, will be less sensitive to distance from boundary and more strongly correlated with edge effects, represented by patch shape indices. 3) Richness patterns of all species will be affected by patch size, in accordance with the Island Biogeography Theory, and matrix resistance to dispersal as expressed by the proportion of impermeable surface (as shown by the patch-matrix framework).

\section{Materials and methods}

\subsection{Study area}

The study was carried out in Kunming city, China $\left(102^{\circ} 10^{\prime} \sim 103^{\circ} 40^{\prime}\right.$ E, $\left.24^{\circ} 23^{\prime} \sim 26^{\circ} 22^{\prime} \mathrm{N}\right)$. Kunming is the largest city of Yunnan Province. It is a biodiversity hotspot located in the center of the Yunnan-Guizhou Plateau in southwestern China (Myers et al., 2000). The city is bordered by Dianchi Lake $\left(330 \mathrm{~km}^{2}\right)$ to the south and surrounded by mountains on the other sides. The city's average altitude is $1,890 \mathrm{~m}$. Kunming has a typical temperate climate with an average annual temperature of $14.5^{\circ} \mathrm{C}$ and a mean annual precipitation of $1035 \mathrm{~mm}$. The city's built-up area covered $75 \mathrm{~km}^{2}$ in 1985 and covers an area of 438 $\mathrm{km}^{2}$ with population of 3.93 million in 2017 (Bureau, 1989; Development, 2017). The rapid urbanization of Kunming has resulted in the removal of most of the remnant native vegetation, a decline in native species and the homogenization of the urban landscape (Yang et al., 
2004). The green space in Kunming has become increasingly fragmented with rapid urban development in recent years. Cultivated and spontaneous plants dominate the species composition in the built-up area.

\subsection{Data collection}

Field surveys of spontaneous plant species were conducted during the growing season between June and October in 2017 and 2018. We treated the lake and the foot of the mountain range as the city's boundary. We delineated a polygon of the city boundary using Google Earth Pro 7.3.2 (Fig.1). Eight transects were set up from the city center, evenly radiating to the city boundary (Fig. 1). Along each transect, a sampling site with a radius of $500 \mathrm{~m}$ was set every $2 \mathrm{~km}$ (Fig. 1). Some sample sites contained large green patches, while others had several small patches contributing $<5 \%$ of the surface area. Depending on the number and size of green patches in each sampling site, we randomly selected 1-10 accessible green patches of different sizes for species richness surveys (Fig. 1). In total 190 patches consisting of six main types of green spaces (Table 1): institutional green space, park green space, protective green space (such as sanitation greenbelts, roadway protection green space, windbreak forest, and grouped greenbelts. They have Sanitation, insulation and security purposes), residential green space, street green space and vacant lands, were surveyed (Zhao et al., 2010). We recorded all plant species in each patch, but only included the

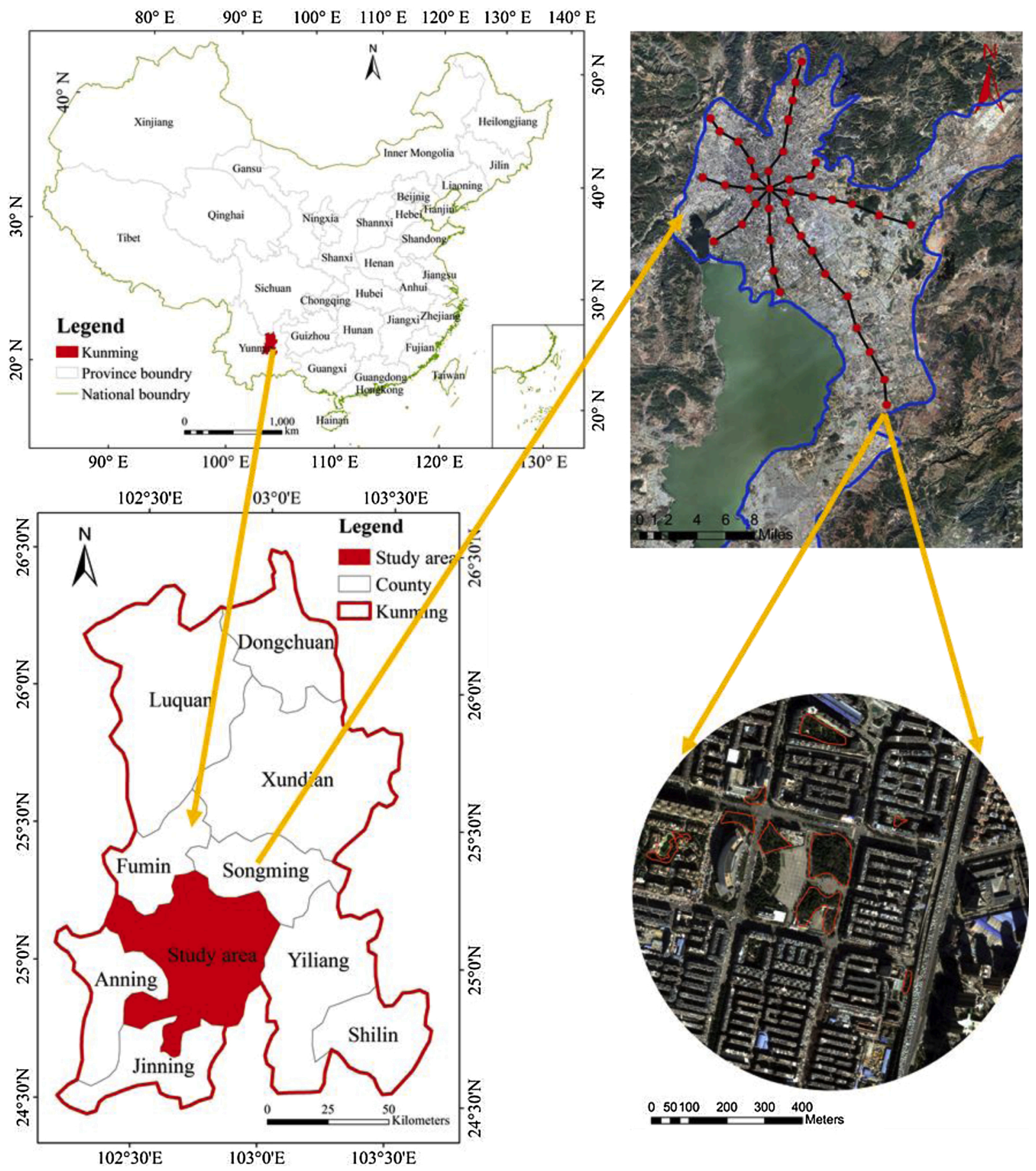

Fig. 1. Location of Kunming city and sample sites. Top right: sampling sites surveyed along the 8 transects in Kunming city and the solid line is the city boundary; Bottom right: an example of a sampling site; Patches surveyed for this sampling site by solid line. 
Table 1

General information of the six types of urban green patches studied in Kunming.

\begin{tabular}{|c|c|c|c|c|c|c|c|c|}
\hline $\begin{array}{l}\text { Type of Green } \\
\text { space }\end{array}$ & $\begin{array}{l}\text { Number of } \\
\text { patches }\end{array}$ & $\begin{array}{l}\text { Mean } \\
\text { patch area } \\
\text { (ha) }\end{array}$ & $\begin{array}{l}\text { Mean distance from } \\
\text { patch to boundary } \\
(\mathrm{km})\end{array}$ & $\begin{array}{l}\text { Proportion of } \\
\text { total surveyed } \\
\text { area }\end{array}$ & $\begin{array}{l}\text { Mean number of } \\
\text { spontaneous species/ } \\
\text { ha }\end{array}$ & $\begin{array}{l}\text { Mean number of } \\
\text { native species/ } \\
\text { ha }\end{array}$ & $\begin{array}{l}\text { Mean number of } \\
\text { non-native } \\
\text { species/ha }\end{array}$ & $\begin{array}{l}\text { Mean number of } \\
\text { invasive species/ } \\
\text { ha }\end{array}$ \\
\hline Institutional & 30 & 1.7 & 4.1 & $17.2 \%$ & 126 & 96 & 3 & 27 \\
\hline Parks & 13 & 4.5 & 3.5 & $19.3 \%$ & 51 & 32 & 0 & 19 \\
\hline Protective & 50 & 1.2 & 6.0 & $20.6 \%$ & 83 & 54 & 2 & 27 \\
\hline Residential & 40 & 0.5 & 4.8 & $6.6 \%$ & 235 & 164 & 4 & 68 \\
\hline Street & 21 & 0.4 & 5.6 & $2.9 \%$ & 144 & 101 & 3 & 40 \\
\hline Vacant land & 36 & 2.8 & 4.2 & $33.4 \%$ & 56 & 37 & 2 & 16 \\
\hline
\end{tabular}

spontaneous species in our analysis. We classified naturally growing herbaceous plants and seedlings of woody plants in all urban man-made green patches as spontaneous species. We excluded fully grown trees because of the difficulty in determining whether they had been intentionally planted or occurred spontaneously, except for those growing on abandoned lands, roofs and walls. The spontaneous species were further classified into native, non-native and invasive species according to the Flora Yunnanica (Wu, 2006), Exotic plants in China (He, 2012) and The Checklist of Chinese Invasive Plants (Ma et al., 2013). We treat the naturalized plants of the book of Exotic plants in China as native species in this analysis. Species classified to the first five invasive levels of The Checklist of Chinese Invasive Plants were defined as invasive species. Although all invasive species are non-native species, in order to better explore differences in the driving factors of different group of species, the non-native species in this study were analyzed separately from the invasive species. We regarded invasive species as a distinct group from other non-native species

Using high-resolution aerial orthophotos (RGB, $0.14 \mathrm{~m}$ resolution, 2018), we manually delineated the boundaries of every surveyed patch using Google Earth Pro 7.3.2 (Google, 2015; the red polygons in the bottom right panel of Fig. 1). These polygons were imported into ArcGIS 10.3 (ESRI, 2015) to calculate patch area, patch perimeter, distance to city boundary and distance to the nearest neighboring patch. High-resolution aerial orthophotographs were classified into five land use categories: sealed surface, barren land, arable land, water, and vegetation, by applying the Maximum Likelihood Classification which is a supervised classification in ArcGIS. The proportion of impervious surface within radii of $25 \mathrm{~m}\left(\right.$ Sealed $\left._{25}\right), 50 \mathrm{~m}\left(\right.$ Sealed $\left._{50}\right), 75 \mathrm{~m}\left(\right.$ Sealed $\left._{75}\right)$ and $100 \mathrm{~m}\left(\right.$ Sealed $\left._{100}\right)$ around the patches were estimated based on this classification. The Euclidean distance between the boundary of two adjacent nearest neighbor patches was calculated using the Near tool in ArcGIS. Perimeter-area ratio and landscape shape index were used to assess edge effects (Gyenizse et al., 2014). Perimeter-area ratio represents the ratio of the perimeter to patch area, and is used to express the edge effect. Landscape shape index (landscape shape index $=$ Perimeter $/ 2 \sqrt{\pi \text { Area }}$ ) represents the degree of deviation of the patch's shape to a perfect circle. The larger the landscape shape index, the more dissimilar it is to a perfect circle.

\subsection{Data analysis}

Exploratory linear regression analyses were conducted to evaluate the individual relationships between the independent variables (patch area, distance to city boundary, landscape shape index, perimeter-area ratio, Sealed ${ }_{25}$, Sealed 50 , Sealed 75 , Sealed ${ }_{100}$, distance to the nearest neighboring patch), and the dependent variables (total number of spontaneous species, number of native species, non-native species and invasive species). Patch area and distance to city boundary were logtransformed to match the assumption of normal distribution of the data. To avoid collinearity among independent variables, a Pearson correlation analysis was employed prior to further analysis. In case where two variables had a correlation coefficient greater than 0.7 , the one with has the highest correlation with the dependent variables was

Table 3

List of non-linear prediction models of spontaneous species richness. A - patch area, BD - distance of patch to urban boundary, LSI - landscape shape index, PA perimeter-area ratio, Sealed $\mathrm{S}_{25}$ - the proportion of sealed surface around the patch within a radius of $25 \mathrm{~m}, \mathrm{NN}$ - distance to the nearest neighboring patch.

\begin{tabular}{|c|c|c|c|}
\hline $\begin{array}{l}\text { Model } \\
\text { No. }\end{array}$ & Model & $\begin{array}{l}\text { Independent } \\
\text { variables }\end{array}$ & Related theories \\
\hline 1 & $\beta_{0} A^{\beta 1}$ & A & Species area curve \\
\hline 2 & $\beta_{0}\left[\log _{10} \mathrm{~A}\right]^{\beta 1}$ & A & Species area curve \\
\hline 3 & $\beta_{0} A^{\beta 1} * \mathrm{e}^{-\beta 2 \log (B D)}$ & $\mathrm{A}, \mathrm{BD}$ & $\begin{array}{l}\text { Island Biogeography } \\
\text { Theory and Species } \\
\text { area curve }\end{array}$ \\
\hline 4 & $\beta_{0}\left[\log _{10} \mathrm{~A}\right]^{\beta 1}{ }_{*} \mathrm{e}^{-\beta 2 \log (\mathrm{BD})}$ & $\mathrm{A}, \mathrm{BD}$ & $\begin{array}{l}\text { Island biogeography } \\
\text { Theory and Species } \\
\text { area curve }\end{array}$ \\
\hline 5 & $\begin{array}{l}\beta_{0}\left[\log _{10} \mathrm{~A}\right]^{\beta 1}{ }_{*} \mathrm{e}^{-\beta 2 \log (\mathrm{BD})}+\beta_{3} \\
\mathrm{e}^{-\beta 4 \log _{10}(\mathrm{LS})}\end{array}$ & $\mathrm{A}, \mathrm{BD}, \mathrm{LSI}$ & $\begin{array}{l}\text { Meta-population and } \\
\text { Patch-matrix } \\
\text { perspective }\end{array}$ \\
\hline 6 & $\begin{array}{l}\beta_{0}\left[\log _{10} \mathrm{~A}\right]^{\beta 1}{ }_{*} \mathrm{e}^{-\beta 2 \log (\mathrm{BD})}+\beta_{30} \\
\mathrm{e}^{\left.-\beta 4 \log _{10} \mathrm{PA}\right)}\end{array}$ & $\mathrm{A}, \mathrm{BD}, \mathrm{PA}$ & $\begin{array}{l}\text { Meta-population and } \\
\text { Patch-matrix } \\
\text { perspective }\end{array}$ \\
\hline 7 & $\begin{array}{l}\beta_{0}\left[\log _{10} \mathrm{~A}\right]^{\beta 1} * \mathrm{e}^{-\beta 2 \log (\mathrm{BD})}+\beta_{30} \\
\mathrm{e}^{-\beta 4 \log (\text { Sealed25) }}{ }_{10}\end{array}$ & A, BD, Sealed 25 & $\begin{array}{l}\text { Meta-population and } \\
\text { Patch-matrix } \\
\text { perspective }\end{array}$ \\
\hline 8 & $\begin{array}{l}\beta_{0}\left[\log _{10} \mathrm{~A}\right]^{\beta 1}{ }_{*} \mathrm{e}^{-\beta 2 \log (\mathrm{BD})}+\beta_{30} \\
\mathrm{e}^{\left.-\beta 4 \log _{10} \mathrm{NN}\right)}\end{array}$ & $\mathrm{A}, \mathrm{BD}, \mathrm{NN}$ & $\begin{array}{l}\text { Meta-population and } \\
\text { Patch-matrix } \\
\text { perspective }\end{array}$ \\
\hline
\end{tabular}

Table 2

Pearson correlation coefficients of independent variables; patch area (A), distance from the patch to city boundary (BD), perimeter-area ratio (PA), landscape shape index (LSI), distance to the nearest neighboring patch (NN), proportion of sealed surface around the patches within different radii $\left(\right.$ Sealed $_{25}$, Sealed ${ }_{50}$, Sealed ${ }_{75}$ and Sealed $_{100}$ ).

\begin{tabular}{|c|c|c|c|c|c|c|c|c|}
\hline & $\log A$ & Log LSI & Log PA & $\log . \mathrm{BD}$ & Log NN & Sealed $_{25}$ & Sealed $_{50}$ & Sealed $_{75}$ \\
\hline Log LSI & 0.301 & & & & & & & \\
\hline Log PA & -0.922 & 0.091 & & & & & & \\
\hline Log.BD & -0.127 & 0.039 & 0.148 & & & & & \\
\hline Log NN & -0.108 & -0.018 & 0.106 & -0.163 & & & & \\
\hline Sealed $_{25}$ & -0.236 & -0.075 & 0.216 & 0.346 & -0.002 & & & \\
\hline Sealed $_{50}$ & -0.205 & -0.05 & 0.194 & 0.368 & 0.013 & 0.94 & & \\
\hline Sealed $_{75}$ & -0.202 & -0.033 & 0.197 & 0.374 & 0.037 & 0.877 & 0.973 & \\
\hline Sealed $_{100}$ & -0.203 & -0.029 & 0.2 & 0.367 & 0.06 & 0.83 & 0.935 & 0.984 \\
\hline
\end{tabular}


selected for further analysis (Table 2).

After the exploratory analysis, eight non-linear regression models (Table 3) were evaluated for each of the four species categories to evaluate their relationships between species richness and potentially driving variables. Patch size is the fundamental parameter in speciesarea curve (Arrhenius, 1921a) and was accounted for in Model 1 and Model 2. Model 3 and Model 4 included the two basic parameters of the Island Biogeography Theory, island size and the distance to the species pool. These two processes were assumed to interact, therefore they were introduced as interactive terms. Next, following metapopulation theory and patch matrix theory concepts, we also considered other patch properties, such as landscape shape index (Model 5), perimeter-area ratio (Model 6), Sealed 25 (Model 7) and distance to the nearest neighboring patch (Model 8) to assess the impacts of highly fragmented landscapes. For Model 7, we only included Sealed 25 to describe the impacts of sealing, because Sealed ${ }_{25}$, Sealed ${ }_{50}$, Sealed $_{75}$ and Sealed 100 turned out to be highly correlated (all correlation coefficients all higher than 0.8 ) and Sealed $d_{25}$ showed the highest correlation with the dependent variable. The parameters introduced to models 5- 8 were assumed to operate independently of patch area and distance to city boundary, thus they were included as additive terms.

Next, we estimated maximum likelihood parameter values for each non-linear model by using the Microsoft Excel optimization engine (Hobbs and Hilborn, 2006; Malkinson et al., 2018). For each spontaneous species group, competing models were ranked using Akaike's Information Criterion (AIC), a metric for relative model fit penalized by model complexity. The Akaike weight (Wr), ranging from 0 to 1 , was used to assess the relative weight of each model, which is analogous to the probability that a given model is the best approximating model (Burnham and Anderson, 2002). To evaluate the fit of the model, the adjusted pseudo- $R^{2}$ was calculated by using the Rsq function of the soilphysics package (version 3.1) (Silva and Lima, 2017) in $R$ version 3.4.1 (RCoreTeam, 2014) (Table 4).

\section{Results}

\subsection{Patch features}

The mean area of the 190 sampled green patches was $15,948 \mathrm{~m}^{2}$, the smallest was $128 \mathrm{~m}^{2}$ and the largest was $398,723 \mathrm{~m}^{2}$. In total, 386 spontaneous plant species from 279 genera and 92 families were recorded. Among these, we recorded 294 herbaceous species (76.2 \%), 42 shrub species (10.9\%), 37 tree species (9.6\%) and 13 liana species (3.4\%). Of all species, 298 (77.2 \%) were native, 19 (4.9\%) were nonnative, and 69 species (17.9\%) were invasive (Appendix A). The most frequent families included Asteraceae and Poaceae (each constituting 46 species, or $11.9 \%$ of the total number of species found), followed by Fabaceae (6.0 \%) and Rosaceae (4.7 \%) (Fig. 2a ). The top ten most frequently sampled species were all herbaceous species. Of these, six were invasive species, and their frequencies were all higher than $50 \%$ (Fig. 2b). The highest and lowest richness of species recorded in a single patch were 148 and 5, respectively, whereas the mean species richness was 35 .

\subsection{Bivariate relationship between richness and patch properties}

The linear relationship between the total number of spontaneous species and patch area $\left(\log _{10}\right.$ scale) was significant $\left(R^{2}=0.36, \mathrm{p}<\right.$ $0.001)$, and so was the relationship for the number of native species $\left(R^{2}\right.$ $=0.35, \mathrm{p}<0.001)$, non-native species $\left(R^{2}=0.12, \mathrm{p}<0.001\right)$ and invasive species $\left(R^{2}=0.28, \mathrm{p}<0.001\right)$ (Fig. 3A). The linear relationship between the total number of spontaneous species and distance to city boundary ( $\log _{10}$ scale) was significant, albeit with a low $R^{2}$ value $\left(R^{2}=\right.$ $0.03, \mathrm{p}<0.05)$, and so was the relationship for the number of native species $\left(R^{2}=0.03, \mathrm{p}<0.05\right)$, and non-native species $\left(R^{2}=0.03, \mathrm{p}<\right.$ $0.05)$. In contrast, the relationship between invasive species and distance to city boundary was not significant $\left(R^{2}=0.02, \mathrm{p}>0.05\right)$ (Fig. 3B). The negative correlation between species richness and Sealed $_{25}$ was only marginally significant for total species $\left(R^{2}=0.02, \mathrm{p}=\right.$ $0.05)$ and native species $\left(R^{2}=0.02, \mathrm{p}=0.06\right)$.

The total number of species $\left(R^{2}=0.17, \mathrm{p}<0.001\right)$, the number of native species $\left(R^{2}=0.16, \mathrm{p}<0.001\right)$, the number of nonnative species $\left(R^{2}=0.06, \mathrm{p}<0.001\right)$ and the number of invasive species $\left(R^{2}=0.15, \mathrm{p}\right.$ $<0.001)$ were found to be negatively correlated with perimeter-area ratio (Fig. 3C). In contrast, the total number of species $\left(R^{2}=0.08, \mathrm{p}\right.$ $<0.001)$, the number of native species $\left(R^{2}=0.07, \mathrm{p}<0.001\right)$, the number of non-native species $\left(R^{2}=0.03, \mathrm{p}<0.05\right)$ and the number of invasive species $\left(R^{2}=0.05, \mathrm{p}<0.05\right)$ were found to be positively and significantly correlated with landscape shape index (Fig. 3D).

\subsection{Non-linear prediction models for species richness}

For total spontaneous plant species, model 5, which included patch area, distance to city boundary and landscape shape index, best explained the richness pattern (Table 3). The associated AIC model weight $(W r=0.889)$ indicated that this model was best supported by the data than any of the other candidate models. Replacement of landscape shape index by perimeter-area ratio or distance to the nearest neighboring patch strongly weakened the model. For native species (Table 3), the models showed a ranking similar to those of the total number species pattern. Again, the data best supported Model $5(W r=0.808)$, and the other competing models were much more poorly supported by the data. When assessing non-native species, the top three models were Model 5 $(W r=0.323)$, Model $8(W r=0.278)$ and Model $6(W r=0.137)$. The similar performance of Model 5 and Model 8 indicates that replacing landscape shape index by distance to the nearest neighboring patch only

Table 4

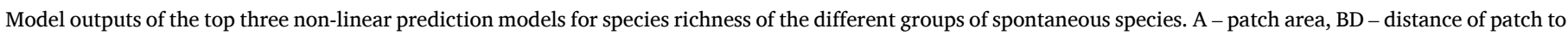

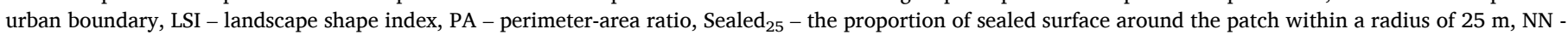

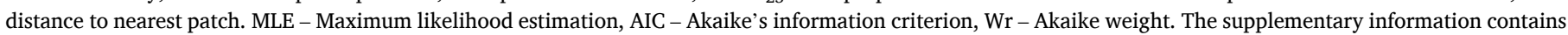
the output of all eight candidate models for each species group (Table B.1).

\begin{tabular}{|c|c|c|c|c|c|c|c|c|c|c|}
\hline species group & Top 3 Models & $\beta_{0}$ & $\beta_{1}$ & $\beta_{2}$ & $\beta_{3}$ & $\beta_{4}$ & MLE & AIC & $W r$ & Adjusted $R^{2}$ \\
\hline \multirow{3}{*}{ Total } & No.5 $\beta_{0}\left[\log _{10} A\right]^{\beta 1}{ }^{-\beta 2 \log (B D)}+\beta_{30} e^{-\beta 4 \log (\mathrm{LSSI})}$ & 0.005 & 6.505 & 0.408 & 20.927 & -0.832 & -772.661 & 1557.782 & 0.889 & 0.467 \\
\hline & No.6 $\beta_{0}\left[\log _{10} \mathrm{~A}\right]^{\beta 1} \mathrm{e}^{-\beta 2 \log (\mathrm{BD})}+\beta_{3} \mathrm{e}^{-\beta 4 \log (\mathrm{PA})}$ & 0.034 & 5.281 & 0.323 & 31.084 & -0.435 & -775.495 & 1563.449 & 0.052 & 0.448 \\
\hline & No.8 $\beta_{0}\left[\log _{10} \mathrm{~A}\right]^{\beta 1} \mathrm{e}^{-\beta 2 \log (\mathrm{BD})}+\beta_{30} \mathrm{e}^{-\beta 4 \log (\mathrm{NN})}$ & 0.008 & 6.171 & 0.382 & 27.434 & 0.140 & -775.936 & 1564.331 & 0.034 & 0.448 \\
\hline \multirow{3}{*}{ Native } & No. $5 \beta_{0}\left[\log _{10} \mathrm{~A}\right]^{\beta 1}=\mathrm{e}^{-\beta 2 \log (\mathrm{BD})}+\beta_{30} \mathrm{e}^{-\beta 4 \log _{10}^{(\mathrm{LSI})}}$ & 0.000 & 9.031 & 0.525 & 18.493 & -0.628 & -704.471 & 1421.401 & 0.808 & 0.464 \\
\hline & No.8 $\beta_{0}\left[\log _{10} A\right]^{\beta 1} * \mathrm{e}^{-\beta 2 \log (\mathrm{BD})}+\beta_{3} \mathrm{e}^{-\beta 4 \log (\mathrm{NN})}$ & 0.000 & 8.721 & 0.512 & 23.703 & 0.130 & -706.816 & 1426.091 & 0.077 & 0.451 \\
\hline & No.6 $\beta_{0}\left[\log _{10} \mathrm{~A}\right]^{\beta 1} \mathrm{e}^{-\beta 2 \log (\mathrm{BD})}+\beta_{30} \mathrm{e}^{-\beta 4 \log 10(\mathrm{PA})}$ & 0.001 & 7.774 & 0.475 & 24.709 & -0.226 & -706.907 & 1426.274 & 0.071 & 0.450 \\
\hline \multirow{3}{*}{ Non-native } & No. $5 \beta 0\left[\log _{10} \mathrm{~A}\right]^{\beta 1} * \mathrm{e}^{-\beta 2 \log (\mathrm{BD})}+\beta 3 \mathrm{e}_{10}^{-\beta 4 \log (\mathrm{LSI})}$ & 0.001 & 6.596 & 0.860 & 0.477 & -1.007 & -242.561 & 497.580 & 0.323 & 0.203 \\
\hline & No.8 $\beta_{0}\left[\log _{10} \mathrm{~A}\right]^{\beta 1} \mathrm{e}^{-\beta 2 \log (\mathrm{BD})}+\beta_{3} \mathrm{e}^{-\beta 4 \log (\mathrm{NN})}$ & 0.001 & 6.260 & 0.835 & 0.319 & -0.523 & -242.711 & 497.881 & 0.278 & 0.201 \\
\hline & No.6 $\beta_{0}\left[\log _{10} \mathrm{~A}\right]^{\beta 1} \mathrm{e}^{-\beta 2 \log (\mathrm{BD})}+\beta_{30} \mathrm{e}^{-\beta 4 \log 10(\mathrm{PA})}$ & 0.001 & 6.002 & 0.740 & 0.687 & -0.273 & -243.415 & 499.290 & 0.137 & 0.195 \\
\hline \multirow{3}{*}{ Invasive } & No. $5 \beta_{0}\left[\log _{10} \mathrm{~A}\right]^{\beta 1} \mathrm{e}^{-\beta 2 \log 10(\mathrm{BD})}+\beta_{3} \mathrm{e}^{-\beta 4 \log 10(\mathrm{LSI})}$ & 0.027 & 4.269 & 0.265 & 5.423 & -0.685 & -550.742 & 1113.944 & 0.247 & 0.298 \\
\hline & No. $3 \beta_{0} \mathrm{~A}^{\beta 1} \mathrm{e}^{-\beta 2 \log 10(\mathrm{BD})}$ & 2.834 & 0.190 & 0.120 & - & - & -552.899 & 1114.015 & 0.238 & 0.293 \\
\hline & No.1 $\beta_{0} A^{\beta 1}$ & 1.823 & 0.192 & - & - & - & -554.298 & 1114.725 & 0.167 & 0.289 \\
\hline
\end{tabular}



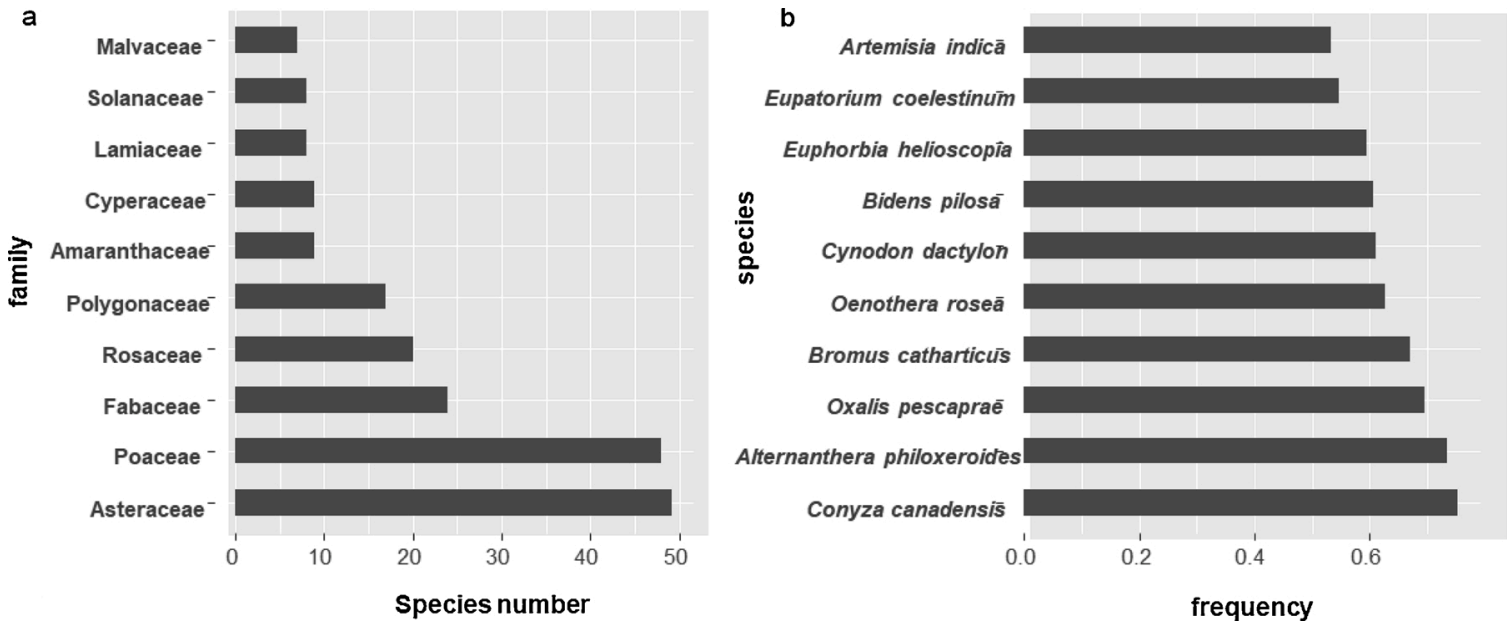

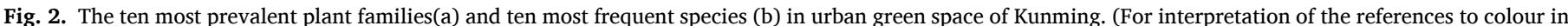
this figure legend, the reader is referred to the web version of this article.)
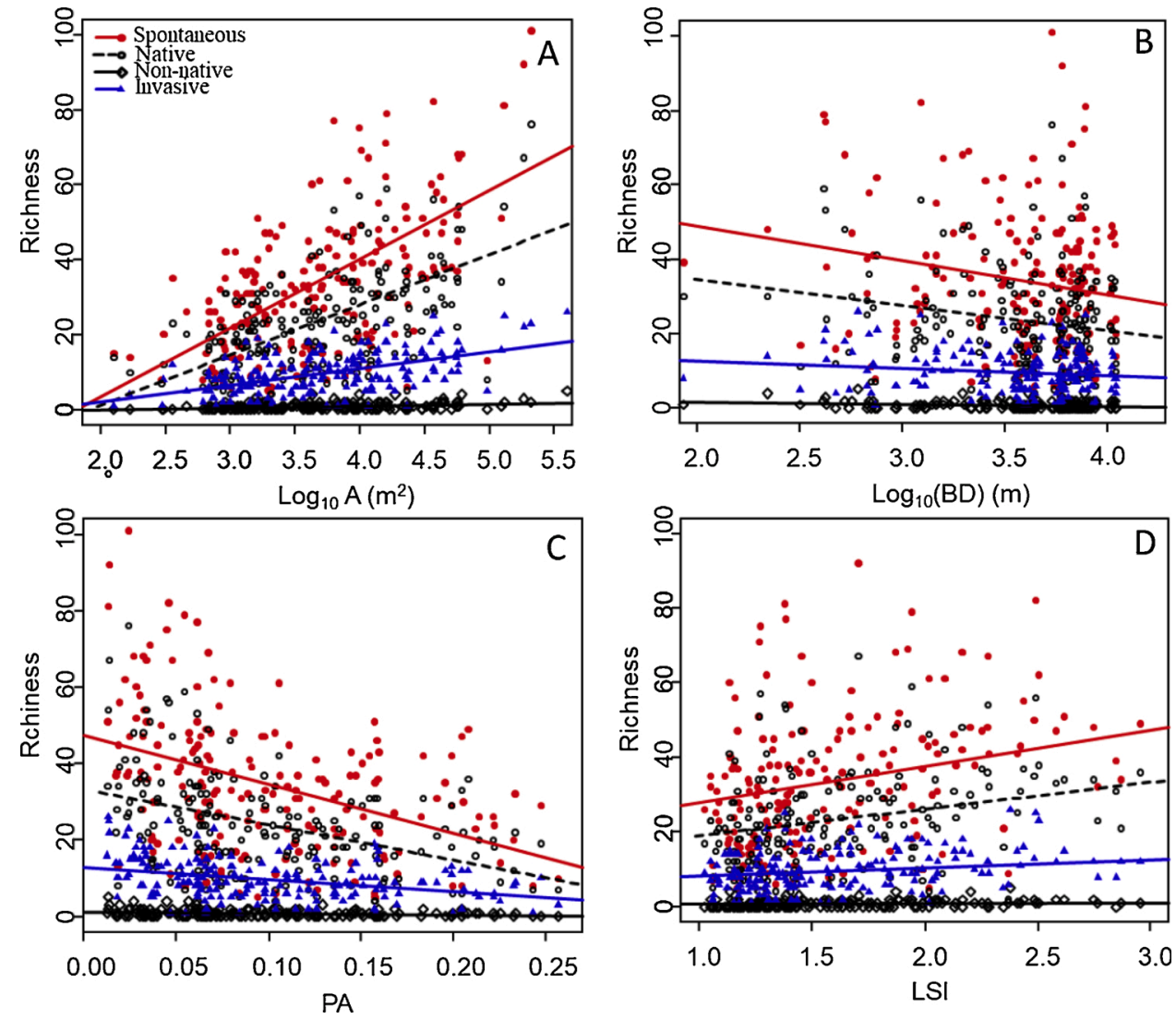

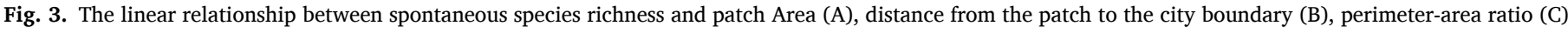
and landscape shape index (D).

slightly weakened the model. Replacing landscape shape index by perimeter-area ratio (Model 6) also weakened the model. As for the invasive species case, Model 5 and Model 3 performed similarly, indicating that removing landscape shape index as an explanatory term only slightly weakened support by the data (Model 5 and 3, $W r=0.247$ and 0.238 , respectively). Removing distance to city boundary and landscape shape index weakened the model (Model $6, W r=0.159$ ).

\section{Discussion}

As an important constituent of biodiversity in urban environments, increasing attention has been paid to the role of spontaneous species. Although studies focused on how urbanization affects natural remnant vegetation and cultivated vegetation in cities, our knowledge on spontaneous plants in urban green spaces is still limited. In this study we investigated the factors driving the richness of four subsets of plant species, the total, native, nonnative and invasive spontaneous species in Kunming, a city which is located at a biodiversity hotspot and 
undergoing rapid urbanization. Our study demonstrated that most (77.2 $\%$ ) of the spontaneous species in the urban area consist of native species. The richness of different spontaneous species categories was best described by the same combination of patch area and distance to city boundary, processes which have been at the foundation of the Theory of Island Biogeography. Additionally, the landscape shape index, which has been brought up in the context of the meta-population approach (Kindvall and Petersson, 2000) and the patch matrix perspective (Ye et al., 2013) has also turned to be an important parameter related to richness patterns.

\subsection{Drivers of spontaneous species richness}

Our linear and non-linear regression analyses showed that habitat properties strongly affected spontaneous species richness patterns. Patch area explained most of the variance of spontaneous species richness in all four groups of spontaneous species, where smaller patches generally contained fewer species than larger patches. These patterns are consistent with some of the well-known ecological concepts such as the Island Biogeography Theory and the associated species-area relationships (Arrhenius, 1921b; Gleason, 1922; MacArthur and Wilson, 1967). Similar positive relationships between area and urban biodiversity have been demonstrated previously (Debinski and Holt, 2000; Angold et al., 2006; Munguía-Rosas and Montiel, 2014; Beninde et al., 2015; Matthies et al., 2015). Moreover, the negative correlation between distance of a patch to the city boundary and spontaneous species richness also conforms with established ecological concepts, e.g. on urban-rural gradients (McDonnell and Hahs, 2008). As Kunming is surrounded by mountains with extensive natural cover, distance to city boundary reflects the "resistance" of gaining access to the local species pool from a patch perspective: the closer the patch is to the city boundary, the more access to the regional natural species pool is expected. Due to the concentric nature of the urbanization progress, distance to city boundary also represents the intensity and the time since urbanization. Our linear and non-linear results both show higher in species richness closer to the city boundary. While some studies showed similar trends along urban-rural gradients (Kim and Pauleit, 2005; Chen et al., 2014; Tian et al., 2015), a meta-analysis of urban-rural gradient studies (McKinney, 2008) indicated that in most (about $65 \%$ ) of the 17 plant studies a higher species richness is associated with moderate urbanization, resembling an intermediate disturbance hypothesis response (McKinney, 2008). The discrepancy of our results might be explained by the fact that these studies did not exclude cultivated species, or that the definition of intensity of urbanization is different. Previous studies used distance to the city center (McDonnell and Hahs, 2008), proportion of impervious surface (Peng et al., 2019), nighttime light levels (Hu et al., 2020) or socio-economic indicators (Fan et al., 2019) to quantify urbanization intensities. Furthermore, Kunming is rapidly developing, and thus species composition dynamics might be far from equilibrium, thus patches near the city's boundary may exhibit an extinction debt (Tilman et al., 1994).

We assumed that distance to nearest patch was an indicator of the degree of habitat connectivity which could affect the dispersal success of spontaneous species. If so, the richness of spontaneous species would increase as the distance to the nearest patch decreases. In the linear regression exploratory analysis, we did not find any significant correlation between distance to the nearest neighboring patch and spontaneous species richness. However, the results of the non-linear prediction models show that the distance to the nearest patch is consistently included in the top three of models for species richness of all groups of spontaneous species, except for invasive plants. This complies with the non-linear long-tailed response of seed dispersal to distance (Nathan et al., 2008).

Species' responses to edge properties vary from increasing and decreasing to no change, depending on the specific edge type encountered (Ries and Sisk, 2004). Within a certain range, an increased edge density or perimeter-area ratio will increase the probability of dispersal and resource availability from neighboring species pools. Meanwhile, the edges disturbance will also increase. Once beyond this range, an increase in these variables may indicate a dispersal barrier among patches. In our case, the landscape shape index represents the degree of deviation between a patch's shape and a perfect circle, where a larger index value represents a more complex patch shape. An increase of landscape shape index can increase the number of habitat types and edge density, and near edges the microclimate (for example, light and water conditions) will also increase (Fahrig, 2017). Additionally, the edge of patches can be viewed as a transition zone where resources are exchanged with neighboring patches. Therefore, a more complex patch shape may have a greater potential to receive resources from neighboring patches (Moser et al., 2002). The edge also differs from the core area of the patches in trophic dynamics, disturbance regime and productivity (Lövei et al., 2006; Haddad et al., 2015), which is likely to affect species richness. We hypothesized that in urban green space the number of spontaneous species is positively related to species dispersal probability between neighboring patches, thus with higher landscape shape index and perimeter-area ratio values. Indeed, the bivariate analysis and non-linear regression analysis both found a positive correlation between landscape shape index and spontaneous species richness, as has been found in many other locations including Beijing (Peng et al., 2019), Chongqing (Wang et al., 2020) and Kwangju (Kim and Pauleit, 2007).

\subsection{Response of different plant categories of species to the urban environment}

Upon dividing all spontaneous species into three categories (i.e. native, non-native and invasive species), the results showed that the same model best explained richness properties for all species categories - model 5. This model accounts for an interaction between patch size and distance to city boundary, and an additive term which accounts for patch geometry, as expressed by landscape shape index. This provides evidence for the importance of patch geometrical properties to species richness. Patch size and distance to city boundary are also key components in the Island Biogeography Theory. However, the application of Island Biogeography Theory in urban environment has a major shortcoming, since the urban matrix may behave differently from true islands (Niemelä, 1999). Patches of equal area might lead to unequal ability to support a given population, as they may differ in the amount of their area exposed to edges (Andren, 1994). Patches of elongated shapes and indented perimeters will experience more disturbance than patches with compact shapes and unbroken perimeters (Helzer and Jelinski, 1999). Furthermore, the patch's surrounding matrix could also result in different degree of patch isolation and hostility (Addicott et al., 1987; Franklin, 1993). Among urban green spaces, species may disperse more successfully than in true island systems, because seed survival is likely to be much lower in the matrix surrounding true islands - i.e., in water bodies (Hanski and Gilpin, 1991; Tilman, 1994). Indeed, the importance of landscape shape index for the distribution of species richness reflects the practical value of the patch matrix and meta-population perspective (Laurance, 2008) in an urbanized world. Malkinson et al. (2018), assessing the richness patterns for different types of species, found that perimeter-area ratio and the habitat types are important variables for dictating species richness in the green space of Haifa, Israel, which also provides evidence for the patch matrix and meta-population perspective. Therefore, we suggested that, when conceptualizing the Island Biogeography Theory in the urbanized world, species dispersal properties and patch geometrical properties should also be considered.

Although invasive species constituted a relatively low proportion of all spontaneous species (17.9\%) and six of the ten most frequent species are invasive ones. Only 19 non-native species (4.9\%) are not invasive. The richness pattern of invasive and non-native species was best explained by the same model as native species, but the relative weight 
$(W r=0.323$ and $W r=0.247)$ and explanatory power $\left(R^{2}=0.203\right.$ and $R^{2}$ $=0.298$ ) of the best model are considerably lower than that of the best model of native species $\left(W r=0.808, R^{2}=0.464\right)$. This different behavior of invasive species may be mainly due to the strong dispersal capacity and reproduction potential of invasive species (Yong Xing, 2010; Chen et al., 2014). Invasive species with higher dispersal ability, for example wind dispersers, have a higher potential to arrive at more distant patches. They also have a tendency for larger reproduction potential, i.e., more seeds, which may increase the number of successful colonization (Coutts et al., 2011). Consequently, distance to city boundary and landscape shape index may have less impact on invasive species richness.

Moreover, the non-native and invasive species are introduced by human activities, and do not depend on the species pool of natural vegetation. Thus, there may be other important factors, such as patch age, that dictate the non-native and invasive species distribution. The establishment of non-native and invasive species may not yet have reached an equilibrium, as is possibly indicated by their small proportion within the total number of spontaneous species. Elsewhere timedelayed colonization takes place in the urban green space (Kopel et al., 2015). Thus, given enough time, also in this study region additional invasive and non-native species are expected to establish. This phenomenon has been described as an "invasion debt" (Essl et al., 2011).

The modelling results, yielded even for the best models, adjusted $R^{2}$ values lower than 0.5 , indicating that there are additional, unaccounted for, drivers of species richness. This may relate to the high socioecological complexity of the urban environment. Besides patch properties, other factors, such as human management, micro-climate, and historical urbanization processes (Flinn et al., 2018) also likely contribute to green patch richness.

While Model 5 consistently was the best one to explain richness patterns, the results suggest that the relative importance of each of these parameters varies among the categories. Although it is incorrect to compare the magnitude of the parameters among the models, due to the different number of species in each category, it is informative to compare the relative contribution of the parameters within each model. For example, for native and invasive species, $\beta_{1}$, which expresses the response of species richness to patch size is 17 and 16 times larger respectively than $\beta_{2}$, which reflects the effects of the distance of the patch size to the city boundary. In contrast, for non-native species this ratio is only approximately 8 , suggesting that patch size is relatively less important compared to native species and invasive species. Similarly, patch shape $\left(\beta_{4}\right)$ in relation to patch area seems to be a much more important factor for dictating native species richness patterns compared to non-native and invasive species. For native species the ratio between $\beta_{1}$ and $\beta_{4}$ is 14 , whereas in the non-native and invasive species case it is only 7 and 6 respectively, highlighting the relative importance of patch shape in the latter. Possibly, this indicates that a more complex patch perimeter structure is associated with increasing colonization potential of the non-native and invasive species, compared to the native ones. Compared to native species, invasive species usually have good performance in urban regions, due to their life history strategy, i.e., a short life span, high dispersal ability, tolerance to stressful environment (Coutts et al., 2011). Therefore, the resistance of the urban landscape to invasive species is lower compare to native ones. Given the horticultural practices within the urban areas, invasive species may have multiple sources throughout the urban region. In contrast, for native species, the species sources are likely to lie outside the city boundaries.

\subsection{Guide for future urban greening space management}

Our study shows that even the potentially harsh heterogeneous environment within a city harbors considerable plant biodiversity. Given their spontaneous nature, by definition, these species can be used for our advantage: their low-maintenance demands and high-adaption characteristics make them ideal candidates for the restoration and reconstruction of habitats. Our results show that the richness of spontaneous plant species in these urban environments relies on the city's morphological properties of the green spaces. Their morphological properties are comprised of the properties of each individual patch, as expressed in this study by the patch area and landscape shape index. When constructing and managing urban green space, urban planners should consider these properties to enhance the species richness of spontaneous species and to enrich the urban green space, especially for patches located away from natural species pools. Due to the critical shortage of urban land, it is not realistic to increase the size of patches when planning green space in urban areas. However, it seems feasible and effective to construct ecological corridors to facilitate dispersal of spontaneous species through the city. Additionally, according to our results, increasing the complexity of green patches' shape might also allow maximizing the diversity of spontaneous species.

In addition, our results show that the different categories of species richness are dictated by the same combination of drivers. This implies that when planning and designing urban green space with increased species richness of native plants, there also exists an increasing risk of species invasion to urban areas. Therefore, additional specific measures might be needed by urban planners and managers to reduce this risk.

Southwestern China, one of the hotspots for biodiversity (Myers et al., 2000), has experienced four decades of rapid urbanization and this trend continues. With an additional tripling of the global urban land cover by 2030 , compared with the year 2000 , this increase is likely to cause considerable additional loss of habitats in key biodiversity hotspots in the future (Seto et al., 2012). Our increased understanding on patterns of spontaneous species richness in these regions will be of importance for developing sustainable practices in urban green space management and to conserve species natural richness.

\section{Author contributions}

Zhiwen Gao: conception, design of the study, data collection, analysis and drafting the manuscript; Yingji Pan: revising the manuscript; Xijin Zhang: analysis and interpretation of data; Bo Jia, Tiyuan Xia, Xueyan Guo, Hong Liang and Shasha Huang: filed survey and identify species; Kun Song and Liangjun Da: design of study, conception, revising the manuscript and final approval of the manuscript; Dan Malkinson, Peter Van Bodegom and Ellen Cieraad: conception, interpretation of data and revising manuscript critically. All authors have read and agreed to the published version of the manuscript.

\section{Declaration of Competing Interest}

The authors declare that they have no known competing financial interests or personal relationships that could have appeared to influence the work reported in this paper.

\section{Acknowledgements}

This research was funded by the National Natural Science Foundation of China (project No. 31770468 and 6622318052), the Ministry of Science and Technology of China (2015FY210200-4), ECNU Academic Innovation Promotion Program for Excellent Doctoral Students (YBNLTS2019-019). We thank Xiaoya Yu from Qiannan Normal University for Nationalities for helping with the species identification.

\section{Appendix A. Supplementary data}

Supplementary material related to this article can be found, in the online version, at doi:https://doi.org/10.1016/j.ufug.2021.127098. 


\section{References}

Addicott, J.F., Aho, J.M., Antolin, M.F., Padilla, D.K., Richardson, J.S., Soluk, D.A., 1987. Ecological Neighborhoods: Scaling Environmental Patterns. Oikos, pp. 340-346.

Alharbi, W., Petrovskii, S., 2019. Effect of complex landscape geometry on the invasive species spread: invasion with stepping stones. J. Theor. Biol. 464, 85-97.

Andren, H., 1994. Effects of Habitat Fragmentation on Birds and Mammals in Landscapes with Different Proportions of Suitable Habitat: a Review. Oikos, pp. 355-366.

Angold, P.G., Sadler, J.P., Hill, M.O., Pullin, A., Rushton, S., Austin, K., Small, E., Wood, B., Wadsworth, R., Sanderson, R., Thompson, K., 2006. Biodiversity in urban habitat patches. Sci. Total Environ. 360 (1), 196-204.

Arrhenius, O., 1921a. Species and area. J. Ecol. 1 (9), 95-99.

Arrhenius, O., 1921b. Species and area. J. Ecol. 9 (1), 95-99.

Avolio, M., Pataki, D.E., Jenerette, G.D., Pincetl, S., Clarke, L.W., Cavender Bares, J., Gillespie, T.W., Hobbie, S.E., Larson, K.L., McCarthy, H.R., 2020. Urban plant diversity in Los Angeles, California: species and functional type turnover in cultivated landscapes, Plants, People. Planet 2 (2), 144-156.

Baum, K.A., Haynes, K.J., Dillemuth, F.P., Cronin, J.T., 2004. The matrix enhances the effectiveness of corridors and stepping stones. Ecology 85 (10), 2671-2676.

Beninde, J., Veith, M., Hochkirch, A., 2015. Biodiversity in cities needs space: a metaanalysis of factors determining intra-urban biodiversity variation. Ecol. Lett. 18 (6) 581-592.

Bonthoux, S., Voisin, L., Bouché-Pillon, S., Chollet, S., 2019. More than weeds: spontaneous vegetation in streets as a neglected element of urban biodiversity. Landsc. Urban Plan. 185, 163-172.

Bureau, K.S., 1989. Kunming Statistical Yearbook 1989. China Statistics Publishing House., Beijing.

Burnham, K.P., Anderson, D.R., 2002. Model Selection and Multimodel Inference: a Practical Information-theoretic Approach. Spnnger-Veflag.

Cavender Bares, J., Cubino, J.P., Pearse, W.D., Hobbie, S.E., Lange, A.J., Knapp, S., Nelson, K.C., 2020a. Horticultural availability and homeowner preferences drive plant diversity and composition in urban yards. Ecol. Appl. 30 (4).

Cavender Bares, J., Padullés Cubino, J., Pearse, W.D., Hobbie, S.E., Lange, A.J., Knapp, S., Nelson, K.C., 2020b. Horticultural availability and homeowner preferences drive plant diversity and composition in urban yards. Ecol. Appl. 30 (4), e02082.

Cervelli, E.W., Lundholm, J.T., Du, X., 2013. Spontaneous urban vegetation and habitat heterogeneity in Xi'an, China. Landsc. Urban Plan. 120, 25-33.

Chen, X., Wang, W., Liang, H., Liu, X., Da, L., 2014. Dynamics of ruderal species diversity under the rapid urbanization over the past half century in Harbin, Northeast China. Urban Ecosyst. 17 (2), 455-472.

Chen, C., Mao, L., Qiu, Y., Cui, J., Wang, Y., 2020. Walls offer potential to improve urban biodiversity. Sci. Rep. 10 (1), 1-10.

Choi, Y.D., 2004. Theories for ecological restoration in changing environment: toward 'futuristic' restoration. Ecol. Res. 19 (1), 75-81.

Coutts, S.R., van Klinken, R.D., Yokomizo, H., Buckley, Y.M., 2011. What are the key drivers of spread in invasive plants: dispersal, demography or landscape: and how can we use this knowledge to aid management? Biol. Invasions 13 (7), 1649-1661.

Cui, Y.C., Song, K., Guo, X.Y., van Bodegom, P.M., Pan, Y.J., Tian, Z.H., Chen, X.S., Wang, J., Da, L.J., 2019. Phylogenetic and functional structures of plant communities along a spatiotemporal urbanization gradient: effects of colonization and extinction. J. Veg. Sci.

De Sousa, C.A., 2006. Urban brownfields redevelopment in Canada: the role of local government. Canadian Geographer 50 (3), 392-407.

Debinski, D.M., Holt, R.D., 2000. A survey and overview of habitat fragmentation experiments. Conserv. Biol. 14 (2), 342-355.

Del Tredici, P., 2010. Spontaneous urban vegetation: reflections of change in a globalized world. Nature + Culture 5 (3), 399-315.

Development, M.O.H.A., 2017. China Urban Construction Statistical Yearbook 2017. China Planning Press Beijing.

E Silva, J.L.S., de Oliveira, M.T.P., Oliveira, W., Borges, L.A., Cruz-Neto, O., Lopes, A.V., 2020. High Richness of Exotic Trees in Tropical Urban Green Spaces: Reproductive Systems, Fruiting and Associated Risks to Native Species. Urban Forestry \& Urban Greening, p. 126659.

ESRI, 2015. ArcGIS 10.3. 1, ESRI Redlands, California.

Essl, F., Dullinger, S., Rabitsch, W., Hulme, P.E., Hulber, K., Jarosik, V., Kleinbauer, I, Krausmann, F., Kuhn, I., Nentwig, W., Vila, M., Genovesi, P., Gherardi, F., DesprezLoustau, M.L., Roques, A., Pysek, P., 2011. Socioeconomic legacy yields an invasion debt. Proc. Natl. Acad. Sci. U.S.A. 108 (1), 203-207.

Fahrig, L., 2017. Ecological responses to habitat fragmentation per Se. Annu. Rev. Ecol. Evol. Syst. 48 (1), 1-23.

Fan, C., Johnston, M., Darling, L., Scott, L., Liao, F.H., 2019. Land use and socioeconomic determinants of urban forest structure and diversity. Landsc. Urban Plan $181,10-21$.

Flinn, K.M., Mahany, T.P., Hausman, C.E., 2018. From forest to city: Plant community change in northeast Ohio from 1800 to 2014. J. Veg. Sci. 29, 297-306.

Franklin, J.F., 1993. Preserving biodiversity: species, ecosystems, or landscapes? Ecol. Appl. 3 (2), 202-205.

Gleason, H.A., 1922. On the relation between species and area. Ecology 3 (2), 158-162.

Groffman, P.M., Cavender-Bares, J., Bettez, N.D., Grove, J.M., Hall, S.J., Heffernan, J.B., Hobbie, S.E., Larson, K.L., Morse, J.L., Neill, C., 2014. Ecological homogenization of urban USA. Front. Ecol. Environ. 12 (1), 74-81.

Gyenizse, P., Bognár, Z., Czigány, S., Elekes, T., 2014. Landscape shape index, as a potencial indicator of urban development in Hungary. Acta. Geograph. Debrecina Landscape Environ. 8 (2), 78-88.
Haddad, N.M., Brudvig, L.A., Clobert, J., Davies, K.F., Gonzalez, A., Holt, R.D., Lovejoy, T.E., Sexton, J.O., Austin, M.P., Collins, C.D., Cook, W.M., Damschen, E.I., Ewers, R.M., Foster, B.L., Jenkins, C.N., King, A.J., Laurance, W.F., Levey, D.J., Margules, C.R., Melbourne, B.A., Nicholls, A.O., Orrock, J.L., Song, D.,

Townshend, J.R., 2015. Habitat fragmentation and its lasting impact on Earth's ecosystems. Sci. Adv. 1 (2), e1500052.

Hanski, I., Gilpin, M., 1991. Metapopulation dynamics: brief history and conceptual domain. Biol. J. Linn. Soc. 42 (1-2), 3-16.

Hanski, I., Ovaskainen, O., 2000. The metapopulation capacity of a fragmented landscape. Nature 404 (6779), 755.

He, J., 2012. Exotic Plants in China. Shanghai Science and Technology Press, Shanghai, p. 761.

Helzer, C.J., Jelinski, D.E., 1999. The relative importance of patch area and perimeter-area ratio to grassland breeding birds. Ecol. Appl. 9 (4), 1448-1458.

Hobbs, N.T., Hilborn, R., 2006. Alternatives to statistical hypothesis testing in ecology: a guide to self teaching. Ecol. Appl. 16 (1), 5-19.

Hu, X., Qian, Y., Pickett, S., Zhou, W., 2020. Urban mapping needs up-to-date approaches to provide diverse perspectives of current urbanization: A novel attempt to map urban areas with nighttime light data. Landsc. Urban Plan 195, 103709.

Huang, L., Qian, S., Li, T., Jim, C.Y., Jin, C., Zhao, L., Lin, D., Shang, K., Yang, Y., 2019. Masonry walls as sieve of urban plant assemblages and refugia of native species in Chongqing, China. Landsc. Urban Plan. 191, 103620.

Ignatieva, M., Stewart, G.H., Meurk, C., 2011. Planning and design of ecological networks in urban areas. Landsc. Ecol. Eng. 7 (1), 17-25.

Itescu, Yuval, 2018. Are island-like systems biologically similar to islands? A review of the evidence. Ecography 42, 1-17.

Jeremy, L., 2011. Vegetation of Urban Hard Surfaces. Urban ecology: Patterns, processes, and applications, pp. 93-102.

Kendal, D., Williams, N.S.G., Williams, K.J.H., 2012. A cultivated environment: exploring the global distribution of plants in gardens, parks and streetscapes. Urban Ecosyst. 15 (3), 637-652.

Kim, K., Pauleit, S., 2005. Landscape metrics to assess the ecological conditions of city regions: application to Kwangju City, South Korea. Int. J. Sustain. Dev. World Ecol. 12 (3), 227-244.

Kim, K., Pauleit, S., 2007. Landscape character, biodiversity and land use planning: the case of Kwangju City Region, South Korea. Land Use Policy 24 (1), 264-274.

Kindvall, O., Petersson, A., 2000. Consequences of modelling interpatch migration as a function of patch geometry when predicting metapopulation extinction risk. Ecol. Modell. 129 (1), 101-109.

Knapp, S., Winter, M., Klotz, S., 2017. Increasing species richness but decreasing phylogenetic richness and divergence over a 320-year period of urbanization. J. Appl. Ecol. 54 (4), 1152-1160.

Kopel, D., Malkinson, D., Wittenberg, L., 2015. Characterization of vegetation community dynamics in areas affected by construction waste along the urban fringe. Urban Ecosyst. 18 (1), 133-150.

Kotze, J., Venn, S., Niemelä, J., Spence, J., 2011. Effects of Urbanization on the Ecology and Evolution of Arthropods, Urban Ecology, Patterns, Processes and Applications. Oxford University Press, New York, pp. 159-166.

Laurance, W.F., 2008. Theory meets reality: how habitat fragmentation research has transcended island biogeographic theory. Biol. Conserv. 141 (7), 1731-1744.

Li, X., Fan, S., Guan, J., Zhao, F., Dong, L., 2019. Diversity and influencing factors on spontaneous plant distribution in Beijing Olympic Forest Park. Landsc. Urban Plan. $181,157-168$.

Lövei, G.L., Magura, T., Tóthmérész, B., Ködöböcz, V., 2006. The influence of matrix and edges on species richness patterns of ground beetles (Coleoptera: carabidae) in habitat islands. Glob. Ecol. Biogeogr. 15 (3), 283-289.

Ma, J.S., Yan, X.L., Shou, H.Y., 2013. The Checklist of the Chinese Invasive Plants. China Higher Education Press, Beijing.

MacArthur, R.H., Wilson, E.O., 1967. Island Biogeography. Princeton.

Malkinson, D., Kopel, D., Wittenberg, L., 2018. From rural-urban gradients to patch matrix frameworks: plant diversity patterns in urban landscapes. Landsc. Urban Plan. 169, 260-268.

Matthies, S.A., Rüter, S., Prasse, R., Schaarschmidt, F., 2015. Factors driving the vascular plant species richness in urban green spaces: using a multivariable approach. Landsc. Urban Plan. 134, 177-187.

McDonnell, M.J., Hahs, A.K., 2008. The use of gradient analysis studies in advancing our understanding of the ecology of urbanizing landscapes: current status and future directions. Landsc. Ecol. 23 (10), 1143-1155.

McKinney, M.L., 2008. Effects of urbanization on species richness: a review of plants and animals. Urban Ecosyst. 11 (2), 161-176.

Moser, D., Zechmeister, H.G., Plutzar, C., Sauberer, N., Wrbka, T., Grabherr, G., 2002. Landscape patch shape complexity as an effective measure for plant species richness in rural landscapes. Landsc. Ecol. 17 (7), 657-669.

Munguía-Rosas, M.A., Montiel, S., 2014. Patch size and isolation predict plant species density in a naturally fragmented forest. PLoS One 9 (10), e111742.

Myers, N., Mittermeier, R.A., Mittermeier, C.G., Da Fonseca, G.A., Kent, J., 2000 Biodiversity hotspots for conservation priorities. Nature 403 (6772), 853.

Nathan, R., Getz, W.M., Revilla, E., Holyoak, M., Kadmon, R., Saltz, D., Smouse, P.E., 2008. A movement ecology paradigm for unifying organismal movement research. Proc. Natl. Acad. Sci. U.S.A. 105 (49), 19052-19059.

Niemelä, J., 1999. Is there a need for a theory of urban ecology? Urban Ecosyst. 3 (1), 57-65.

Peng, Y., Mi, K., Wang, H., Liu, Z., Lin, Y., Sang, W., Cui, Q., 2019. Most suitable landscape patterns to preserve indigenous plant diversity affected by increasing urbanization: a case study of Shunyi District of Beijing, China. Urban For. Urban Green. 38, 33-41. 
Pickett, S.T., Cadenasso, M.L., Grove, J.M., Nilon, C.H., Pouyat, R.V., Zipperer, W.C., Costanza, R., 2001. Urban ecological systems: linking terrestrial ecological, physical, and socioeconomic components of metropolitan areas. Annu. Rev. Ecol. Syst. 32 (1), 127-157.

Pickett, S.T., Cadenasso, M.L., Grove, J.M., 2004. Resilient cities: meaning, models, and metaphor for integrating the ecological, socio-economic, and planning realms. Landsc. Urban Plan. 69 (4), 369-384.

RCoreTeam, 2014. R Version 3.4. 1.

Ries, L., Sisk, T.D., 2004. A predictive model of edge effects. Ecology 85 (11), 2917-2926.

Saura, S., Bodin, Ö., Fortin, M.J., 2014. EDITOR'S CHOICE: stepping stones are crucial for species' long-distance dispersal and range expansion through habitat networks. J. Appl. Ecol. 51 (1), 171-182.

Seto, K.C., Güneralp, B., Hutyra, L.R., 2012. Global forecasts of urban expansion to 2030 and direct impacts on biodiversity and carbon pools. Proc. Natl. Acad. Sci. U.S.A. 109 (40), 16083-16088.

Silva, A.R., Lima, R.P., 2017. Determination of maximum curvature point with the R package soilphysics. Int. J. Curr. Res. 9, 54241-45245.

Smith, L.S., Fellowes, M.D.E., 2014. The grass-free lawn: management and species choice for optimum ground cover and plant diversity. Urban For. Urban Green. 13 (3), 433-442.

Sudha, P., Ravindranath, N.H., 2000. A study of Bangalore urban forest. Landsc. Urban Plan. 47 (1-2), 47-63.

Tian, Z., Song, K., Da, L., 2015. Distribution patterns and traits of weed communities along an urban-rural gradient under rapid urbanization in Shanghai, China. Weed Biol. Manag. 15 (1), 27-41.
Tilman, D., 1994. Competition and biodiversity in spatially structured habitats. Ecology 75 (1), 2-16.

Tilman, D., May, R.M., Lehman, C.L., Nowak, M.A., 1994. Habitat destruction and the extinction debt. Nature 371 (6492), 65-66.

Von der Lippe, M., Kowarik, I., 2008. Do cities export biodiversity? Traffic as dispersal vector across urban-rural gradients. Divers. Distrib. 14 (1), 18-25.

Wang, H.Y., Huang, Y., Wang, D.R., Chen, H., 2020. Effects of urban built-up patches on native plants in subtropical landscapes with ecological thresholds-A case study of Chongqing city. Ecol Indi 108, 105751.

Wu, Z., 2006. Flora Yunnanica. Biostor, pp. 1-795.

Yang, Y., Tian, K., Hao, J., Pei, S., Yang, Y., 2004. Biodiversity and biodiversity conservation in Yunnan, China. Biodivers. Conserv. 13 (4), 813-826.

Ye, X., Skidmore, A.K., Wang, T., 2013. Within-patch habitat quality determines the resilience of specialist species in fragmented landscapes. Landsc. Ecol. 28 (1), 135-147.

Yong Xing, W., 2010. Research of Beijing Biodiversity Assessment.

Zhao, S., Da, L., Tang, Z., Fang, H., Song, K., Fang, J., 2006. Ecological consequences of rapid urban expansion: shanghai, China. Front. Ecol. Environ. 4 (7), 341-346.

Zhao, J., Ouyang, Z., Zheng, H., Zhou, W., Wang, X., Xu, W., Ni, Y., 2010. Plant species composition in green spaces within the built-up areas of Beijing, China. Plant Ecol. 209 (2), 189-204.

Zhu, Z., Roeder, M., Xie, J., Nizamani, M.M., Friedman, C.R., Wang, H., 2019. Plant taxonomic richness and phylogenetic diversity across different cities in China. Urban For. Urban Green. 39, 55-66. 